\title{
Reabilitação Psicossocial e ACOMPANHAMENTO TERAPÊUTICO: EQUACIONANDO A REINSERÇÃO EM SAÚdE MENTAL
}

\author{
PSyChOSOCIAL REHABILITATION AND THERAPEUTIC \\ ACCOMPANIMENT: EQUATING THE REINSERTION IN MENTAL HEALTH \\ ReHABILITACIÓN PSicosocial e ACOMPAŃamiento \\ TERAPÉUTICO: SOSTENIENDO LA REINSERCIÓN EN SALUD MENTAL
}

Viktor Gruska* Magda Dimenstein**

\section{Resumo}

Este artigo objetiva tecer algumas consideraçôes teóricas voltadas ao trabalho de acompanhamento terapêutico (AT) junto a egressos de longas internaçóes psiquiátricas. Busca articular o AT em uma dimensão reabilitadora a qual visa o aumento do grau de autonomia, de funcionamento psicossocial e integraçáo comunitária desses usuários. Consideradas como práticas articuladas ao contexto de vida diário dos usuários, a reabilitação psicossocial e o acompanhamento terapêutico são estratégias potentes que podem contribuir para a expansão do modelo de Atenção Psicossocial e garantia dos direitos dos usuários com transtornos mentais, em especial no que tange à assistência e suporte social. Distanciada de uma acepção adaptacionista, a reabilitação como possibilidade de recontratualização social, em articulação à prática do AT, pode ajudar a equacionar o desafio da reinserção social posto atualmente à política de saúde mental no Brasil. Ou seja, pode ser um dispositivo de ampliaçáo das possibilidades de circulação na cidade e de estruturação da vida cotidiana, auxiliando a evitar o isolamento, o abandono, a cronificação e a institucionalização tão frequentes nessa população que vivencia uma variedade de violações de direitos.

Palavras-chave: reabilitação psicossocial; acompanhamento terapêutico; saúde mental; reinserção social.

\footnotetext{
* Universidade Federal do Rio Grande do Norte, Natal, RN, Brasil.

** Universidade Federal do Rio Grande do Norte, Natal, RN, Brasil.
} 


\section{Abstract}

This paper aims to weave some theoretical considerations directed at the practice of therapeutic accompaniment (TA) with long-term patients discharged from psychiatric hospitals. It seeks to articulate the TA in a rehabilitative dimension which aims to increase the degree of autonomy, psychosocial functioning and community integration of these users. Regarded as practices articulated to the users' daily life context, the psychosocial rehabilitation and the therapeutic accompaniment are powerful strategies which may contribute to the expansion of the psychosocial care mode and to ensure the rights of users with mental disorders, especially regarding assistance and social support. Distanced from an adaptationist perspective, the rehabilitation as a social recontracting possibility, in conjunction with the practice of TA, may help to equate the challenge of social reinsertion currently put to mental health policy in Brazil. In other words, they may become a device to expand the possibilities of movement in the city, to structure everyday life, helping to avoid the isolation, the abandonment, the chronicity effect and the institutionalization, so frequently observed in this population which experiences a variety of rights violation.

Keywords: psychosocial rehabilitation; therapeutic accompaniment; mental health; social reinsertion.

\section{RESUMEN}

Este artículo tiene como objetivo discutir la práctica del acompañamiento terapéutico (AT) con pacientes egresos de los hospitales psiquiátricos. Busca articular el AT con la propuesta de rehabilitación asociada al aumento del grado de autonomía, de funcionamiento psicosocial e integración comunitaria de los usuarios. Consideradas prácticas articuladas con el espacio y el tiempo cotidiano del paciente, la rehabilitación psicosocial y el AT son estrategias de gran alcance que pueden contribuir a la expansión del modelo psicosocial y garantizar los derechos de los usuarios con trastornos mentales, particularmente en relación con la salud y apoyo social. Alejada de una perspectiva adaptacionista, la rehabilitación torna posible el contrato social y junto con la práctica del AT, puede efectivar la propuesta de reinserción propuesta en la política de salud mental en Brasil. Es decir, son un dispositivo que trabaja para facilitar el lazo social, la estructuración de la vida cotidiana, evitando el aislamiento, el abandono, la institucionalización y la cronicidad, tan frecuentes en esta población que experimenta una variedad de violaciones de sus derechos.

Palabras-clave: rehabilitación psicosocial; acompañamiento terapéutico; salud mental; reinserción social. 


\section{Introduçáo}

Objetivando contribuir com o aprimoramento dos instrumentos clínicos de reabilitação e para o avanço das estratégias de reinserção social atualmente produzidas no campo da saúde mental, buscar-se-á compartilhar neste artigo algumas consideraçóes teóricas e apontamentos técnicos voltados ao trabalho de acompanhamento terapêutico (AT) junto a egressos de longas internações psiquiátricas.

Focaremos nosso escopo analítico na dimensão reabilitadora do AT, examinando-a mediante comparação aos princípios clínico-epistêmicos derivados da proposta de Reabilitação Psicossocial (RP) de Benedetto Saraceno (1996; 1999) ${ }^{1}$. Em sintonia com as diretrizes internacionais que preconizam que o cuidado em saúde mental (acesso e qualidade) está na dependência direta do aumento do grau de autonomia pessoal, funcionamento psicossocial e integração comunitária de usuários, consideramos que as possibilidades de análise e aperfeiçoamento do dispositivo AT através de sua articulaçấo ao modelo sociopolítico proposto por Saraceno podem contribuir para a expansão do modelo psicossocial de cuidado e para a consolidação dos direitos e garantias dos usuários com transtornos mentais, em especial no que tange a assistência e suporte social.

Tal articulação está amparada em uma perspectiva de reabilitação que visa ampliar as possibilidades de integraçáo social e sentido de pertencimento comunitário, de circulação na cidade, de estruturação da vida cotidiana. Busca-se o avanço na desinstitucionalização do tratamento, o desmonte do aparato político-ideológico que alimenta a tutela e a segregação manicomial e, portanto, a produção de estratégias reabilitativas capazes de fazer frente ao isolamento, ao abandono e à cronificação tão frequentes nessa população, a qual vivencia cotidianamente uma variedade de violação de direitos.

\section{Reabilitaçáo Psicossocial: tendências em curso}

De início, devemos considerar a inexistência de qualquer conceituação consensual para os modelos operativos de reabilitaçáo psicossocial. No cenário internacional não observamos uma tendência única em relação à pratica e às proposiçóes sobre o tema. Geralmente estão alicerçadas em pressupostos divergentes e incapazes de ofertar sustentação a uma estrutura coesa ou sistematizada de teorias e modos de intervenção (Saraceno, 1996). Sob as plurais formas e usos dessa tecnologia subjazem paradoxos epistêmicos donde vertem projetos clínicos diametralmente opostos, apartados em seus horizontes políticos e, portanto, em 
suas aplicações metodológicas. Assim sendo, as experiências na consolidação do campo da reabilitação em saúde mental dão-se sobre um plano de forças complexo, heterogêneo e crivado por contradições internas, o qual enseja estratégias reabilitadoras ora coadunadas ao atual contexto da reforma psiquiátrica, ora contrárias aos princípios e diretrizes que norteiam sua efetivação.

As principais divergências gravitam em torno de três eixos que entrecortam as práticas de reabilitação orientando suas perspectivas teóricas e posicionamentos clínico-políticos. Tais eixos ou categorias de análise dizem respeito à função $e$ alcance da reabilitação, à definição dos cenários reabilitativos e à conceituação e operacionalização do construto autonomia (Guerra, 2004). A articulação das repostas produzidas para essas categorias configuram os territórios a partir dos quais os diferentes modelos (1) concebem o ambiente social do usuário e seu grau de influência no processo reabilitativo, (2) problematizam as interaçóes entre o contexto de vida do usuário, sua família e a relação terapêutica, estabelecidas na reinserção social, bem como (3) identificam as linhas prioritárias de ação, as habilidades e competências a serem desenvolvidas e os recursos terapêuticos para desenvolvê-las.

Neste trabalho, a perspectiva de reabilitação psicossocial que nos orienta é dada a partir da crítica dos modelos adaptacionistas derivados da tradição psiquiátrica kraepeliana, para os quais o transtorno mental e as desabilitaçóes psicossociais dele decorrentes se produzem desconexos dos marcos sociopolíticos da realidade em que ocorrem, obedecendo a um regime de deterioração progressiva e irreversível das funçôes normais do indivíduo. Assentados sobre a nosologia biomédica e dirigidos por uma perspectiva utilitarista, tais modelos propositam a adequação do paciente às demandas normativas de seu ambiente social, produzindo práticas que, concebidas na ausência de uma maior problematização sobre a relação loucura-cidadania, focam na correção intransitiva dos comportamentos desviantes e na ortopedização da dinâmica sócio familiar do paciente (Saraceno, 1996). Não raro essas iniciativas encontram-se apartadas das complexas constelaçóes de variáveis que constituem os fatores de risco e proteção para as hipofunçóes e desabilitaçóes associadas ao transtorno mental e à cronificação dos pacientes psiquiátricos, o que resulta em abordagens descontextualizadas e pouco flexíveis, baseadas na operacionalização de um saber nosográfico restrito aos aspectos individuais e sintomáticos do transtorno e alheio à materialidade da vida cotidiana.

Ao desconsiderarem a multiplicidade de fatores políticos, econômicos e socioculturais que compóe a dimensão etiológica dos transtornos e, por ignorarem os diferentes sentidos, sentimentos e propósitos que os pacientes atribuem aos seus sintomas, os modelos adaptacionistas de reabilitação tendem a interpretar 
autonomia como um gradiente para a mensuração do ajustamento a protótipos de normalidade cujas hirtas fronteiras servem à delimitaçáo daqueles que estão habilitados ou não para a vida (Lussi, Pereira, \& Pereira Junior, 2006). No campo da prática, essa interpretação amiúde produz propostas homogeneizantes e generalizadas de intervenção que, por meio da supressão de comportamentos "inadequados", buscam o reparo e o melhoramento funcional dos sujeitos não ajustados com vista a reconduzi-los às regras do jogo social (náo importando o quanto segregadoras ou excludentes estas possam ser). Ademais, subtraída da crítica das razôes sociais e políticas do processo reabilitador, tal conceituação, quando posta em uso, opera à semelhança do modelo darwinista de funcionamento social, produzindo a seleção dos sujeitos considerados aptos à reabilitação e o abandono e desresponsabilização dos casos graves (Saraceno, 1999).

$\mathrm{Na}$ busca pela adequação dos sujeitos à previsibilidade da normose social, a reabilitação renuncia ao interesse pela compreensão dos processos individuais de subjetivação, favorecendo a retificação da anacrônica nosografia psiquiátrica. Tamponam, assim, as possibilidades de reconhecimento e valorização das singulares significaçôes por meio das quais cada indivíduo inscreve-se em seu sofrimento e interpreta seu modo de estar no mundo. A partir daí ocorre uma obliteração do sentido do sintoma, pois este não mais é entendido enquanto um modo de enfrentamento a um rompimento com a realidade, mas sim como a expressão de um funcionamento que se produz à revelia do quadro sociopolítico e cuja irrupção demanda imediata remissão (Guerra, 2004). A multitude de pensamentos, afetos e desejos que pululam sob a superfície do mal-estar tornam-se, desse modo, ruídos que, por interferirem nas tentativas de padronizaçáo do comportamento, devem ser silenciados por meio da sedaçáo química e do controle normatizador dos atos anômalos que produzem.

Nesse tocante, há uma questão que nos parece ser de fundamental importância para a problematização do propósito da ação reabilitadora. $\mathrm{Na}$ acepção adaptacionista da reabilitação, o processo de reinserção social e retomada da vida pública não se vincula ao campo de possibilidades e interesses do paciente, posto estar desenraizado da materialidade dos agenciamentos afetivos e enlaces sociais por meio dos quais ele articula cotidianamente seu modo único e irredutível de experienciar o mundo. Tal desconexáo tem como causa e efeito impor aquilo que o sujeito deveria ser, a que injunçóes precisa curvar-se para poder ser aceito, para adequar-se socialmente ou para extirpar seu sofrimento. Trata-se da operacionalização de uma dietética orientada para a docilizaçáo e ajustamento do paciente à libido dominandi, à lógica e ao tempo da racionalidade instrumental (Maffesoli, 2011). Com efeito, as aspirações mesocráticas e universalistas dessa prática resul- 
tam de um sustentáculo acrítico e estigmatizador, tal seja a ideia de que todas as variâncias de hábitos, comportamentos e preferências do louco subsistem como erros, anomalias, aberraçóes à espera da sanção normalizadora da homogeneidade dominante. É precisamente nesse alicerçamento que a RP abandona sua potência inventiva e, junto a ela, sua mais importante função, a de indicar o que poderia ser, a de apontar e construir existências plausíveis, livres do pensamento conformista e da moralização banal dos hábitos e costumes.

Contudo, provocar rupturas no sustentáculo das proposições adaptacionistas a fim de produzir livres experimentaçóes, fundadas no conflito e na negociação, abertas à compreensão da diferença, requer a troca da confortável certeza dos axiomas estabelecidos pelo questionamento incessante e radical das diversas formas do poder instituído. Trata-se de buscar a compreensão das práticas reabilitadoras no interior das articulaçóes históricas, conceituais e políticas que lhes conferem materialidade, propositando decodificar as relaçóes de poder, de dominação e de luta sobre as quais se estabelecem e funcionam (Rodrigues, 2000). Certamente tal esforço sugere o abandono das fórmulas clínico-políticas ortodoxas, cujas conjecturas teóricas, norteadas por uma concepção de sujeito abstrato e descontextualizado historicamente, encontram-se problematicamente alienadas das relaçóes materiais e do regime de signos que as agenciam (Dutra, 2004). Fórmulas que reduzem a libido sciendi à libido dominandi, culminando em um pensamento apriorístico e moralizador a martelar ad nauseam como as coisas deveriam ser (Maffesoli, 2011).

No processo de reabilitação psicossocial, essa imposição normalizadora pode ser usualmente observada quando, associado à indiferença pelas particularidades e interesses do paciente, procura-se reintegrá-lo ao corpo social sem que se tenha buscado o estabelecimento de vias reais para a expansáo de sua capacidade contratual nos planos da habitação, do trabalho e da família, isto é, na ausência de qualquer transformação dos modos de funcionamento e dos lugares sociais impostos, cristalizados na interpretação de constituírem a única maneira possível de existir no mundo (Fiorati \& Saeki, 2006).

Intervenções terapêuticas desenvolvidas nessa direção tornam-se politicamente débeis, posto sofrerem da incapacidade de produzirem redes efetivas de negociação social, necessárias tanto ao provimento de oportunidades para trocas simbólicas entre o usuário e seu entorno cultural, quanto à construção de novos contratos sociais, legitimados no interior da estrutura de funcionamento societal, a partir dos quais possam articular interesses e necessidades próprios à participação na produção de mercadorias e valores (Saraceno, 1996). Sendo assim, tais intervenções não agregam valor ou sentido para a existência dos reabilitandos, 
pois os mantêm alienados dos sistemas de negociação social, cerceando suas possibilidades de arquitetar devires plenos de potência vital.

Dessa tentativa de reinserção, desvinculada do campo das negociaçóes sociais e marcada pela submissão e obediência às segregatórias normas de convivência urbana, decorre uma reintrodução abrupta do paciente num espaço social topologicamente caracterizado por práticas de exclusão, o qual, sem qualquer modificação, tende a permanecer pouco apto a dialogar com a diferença. Por um lado, sabemos que tal modo de reinserção costuma produzir nos familiares (seja pela total responsabilizaçáo do cuidado, insuficiente preparo ou ausência de suporte comunitário) uma sobrecarga de atribuições, com consequente deterioração dos vínculos estabelecidos junto ao usuário (Galdós \& Mandelstein, 2009). Por outro, corre-se o risco de tentar transformar o louco num "sujeito da razão e vontade" para conformá-lo ao corpo social e com isso mantê-lo indeterminadamente preso a testes, avaliaçóes e treinamentos, nunca considerado habilitado (Benetton, 1996).

Sabemos também que fatores ambientais desempenham um papel fundamental no processo de desfiliação e de progressiva diminuição das articulações sociais, e que existe uma ligação entre as expectativas e exigências das pessoas com as quais o paciente interage e a forma com que ele desenvolve sua competência social (Cases \& González, 2010). Assim sendo, observamos que práticas discriminatórias, violências físicas e simbólicas, atos de recusa e negligência perpetrados por aqueles que fazem parte do seu espaço social comprometem gravemente o desenvolvimento de suas habilidades sociais, pois produzem em seu campo de experimentação percepções e sentimentos incapacitantes de falência, frustração e autodepreciação (Saraceno, 1999). A constante exposição a essas práticas faz com que o paciente comece a evitar qualquer situação de interação, posto que sob um contexto estigmatizador aprende que suas tentativas de contato tendem a produzir, de imediato, reaçóes negativas nos sujeitos com os quais busca se relacionar. Um isolamento cada vez mais acentuado constitui-se através deste processo, no qual a competência social que apresenta embota conforme sua dessocialização amplia-se. Estabelece-se nesse ponto uma relação circular e os efeitos das interaçóes inexitosas passam a retroalimentá-las (Lussi et al., 2006).

Parece-nos ser sobre as derivaçóes que potencialmente pode exercer nesse circuito fechado que a RP deve ser mais bem desenvolvida e avaliada. Talvez seja aí, quando o usuário acredita ser incapaz, tornando-se cada vez mais apático frente a esses obstáculos, que a reabilitação precise intervir prioritariamente. Não falamos, portanto, da extinção absoluta e permanente dos sintomas, tampouco da regulaçáo da loucura pelo controle do discurso e dos atos do paciente. Tomar 
tais proposiçóes como ideal de cura ou condição de possibilidade para reinserção daria ensejo para uma reedição, no interior da prática reabilitadora, daquilo que Birman (1992) nomeou de pedagogia da sociabilidade: uma ortopedia moral conduzida pelo entendimento que ao louco faltariam os atributos necessários ao exercício da cidadania, ou seja, um procedimento de correção dos excessos e desvios de um corpo doente que, por não apresentar a capacidade racional e volitiva de gozar de direitos e cumprir deveres, não estaria apto à convivência social.

Contrariamente a esse entendimento, acreditamos que a reabilitação psicossocial deve planejar e estruturar seus esforços terapêuticos sobre as necessidades concretas de moradia, trabalho e socialização apresentadas por cada paciente, expandindo seu escopo de ação para além das consequências sintomáticas mais imediatas do sofrimento psíquico. Trata-se de facilitar aos indivíduos com limitaçóes a restauração no melhor nível possível de autonomia de suas funçóes na comunidade (Pitta, 1996), auxiliando-os na superação da identidade e da trajetória de doente psiquiátrico e na remitência dos efeitos comórbidos associados a essa condição, quais sejam a pobreza, o desemprego, a interdição das possibilidades de participação política, as dificuldades de acesso à educação formal, a invisibilização e o isolamento social (Basaglia, 2005; Lussi et al., 2006).

Podemos assim pensá-la como um processo gradual e complexo de "reconstrução, um exercício pleno de cidadania e, também, de plena contratualidade nos três grandes cenários: hábitat, rede social e trabalho com valor social" (Saraceno, 1996, p. 16). Nesse sentido, a reabilitação caracteriza-se como uma prática clínica diretamente conectada às variáveis reais da vida do paciente, as quais não estão restritas à sua doença, tampouco existem fora da inelutável articulação entre sujeito, ambiente e intersubjetividade. São essas variáveis, resultantes das múltiplas interaçóes que cada indivíduo estabelece cotidianamente no seu entorno social, que nos permitem identificar quais técnicas e conceptualizaçóes são necessárias para a construção de planos de reabilitação, específicos e singularizados, capazes de minorar efetivamente a vulnerabilidade social dos pacientes e ampliar suas oportunidades de trocas materiais e afetivas, aumentando assim seu poder de contratualidade e suas possibilidades de escolha (Lussi et al., 2006).

É no âmbito dessas ideias que a construção - caracteristicamente pragmática, processual e dialógica - da proposta de reabilitação psicossocial posta por Saraceno $(1996 ; 1999)$ produz seu aparelhamento heurístico. Compreendendo o reabilitando como um indivíduo historicamente inscrito, complexo, indivisível e em contínua reorganização, a abordagem biopsicossocial que atravessa a estrutura técnico-conceitual desse modelo está articulada à necessidade de se encontrar estratégias de ação adequadas às necessidades específicas de cada sujeito (vinculadas 
em maior grau à sua vida mundana do que à sintomatologia psiquiátrica que manifesta).

Tal modelo foca-se, portanto, nas dimensóes políticas e sociais do processo reabilitador, orientando-se pela ideia de que não existem desabilidades descontextualizadas do conjunto de determinantes econômicos, culturais e político-sanitários presentes na realidade do paciente, tampouco instrumentos de diagnóstico, tratamento ou reabilitaçáo que não estejam referidos à disponibilidade dos atores, recursos e à conjuntura sócio-histórica dos cenários onde ocorrem as intervençôes. Com efeito, a ênfase terapêutica desse modelo está na produção de redes de negociação construídas na articulação entre paciente/serviço/comunidade e direcionadas ao aumento da participação social e do poder de contratualidade do mesmo. Segundo Saraceno (1999), é no interior da dinâmica de trocas proporcionada por essas redes que se produz o efeito habilitador da RP - pensado em termos da estruturação de novas ordenaçóes para a vida - e, por conseguinte, a melhora clínica. Tal proposição caracteriza aquilo que o autor denomina de clínica do sujeito centrada na produçáo de sentido, perspectiva radicalmente oposta às ortopedias dos modelos adaptacionistas.

Não obstante, do ponto de vista clínico-político, transformar a reabilitação num campo de experimentação para novos projetos de vida, dirigidos ao empoderamento afetivo e político dos pacientes, capaz de produzir devires dotados de sentido e propósito, requer do reabilitador a capacidade de exame e o ímpeto crítico para questionar o plano de forças em que opera. Deve buscar aí compreender os fluxos vitais e os vetores de força que subjazem aos poderes instituídos, mas, outrossim, as resistências micropolíticas em contínua reacomodação no interior da vida social, pois é precisamente nessa busca que residem as condiçóes de possibilidade para a invenção de novas formas de sociabilidade, para a criação de outros arranjos de poder, para a instauração de uma nova relação de forças entre a loucura e a cidade (Palombini, 2009).

Nesse esforço para produzir fissuras na homogeneidade dominante, exercício imanente de devir-diferença do preconceito, a reabilitação psicossocial pode operar como um arranjo terapêutico incoativo, em permanente montagem e sob constante avaliação, engajado com a produçáo de novos territórios, com o desmonte dos regimes de saber-poder inaptos a aceitar dissonâncias, com a desconstrução das práticas e discursos que obstaculizam o conflito e a negociação social. Pois, de fato, é em função das solidariedades comunitárias, das amizades, dos territórios de encontro, espaços de errância, que se estabelecem as redes de influência, as camaradagens e outras formas de ajuda mútua que constituem a matéria viva da reabilitação. 
Trata-se, então, de produzir cosmologias que reinventem as regras do jogo social, "a partir de contra memórias, histórias, sujeitos, experiências e modos de poder excluídos, ignorados e silenciados, um exercício intercultural que não seja apenas uma 'tolerância' clássica, mas sim respeito e diálogo com outros pontos de vista mais abertos e solidários" (Baldi, 2013). E tal movimento de reinvençáo exige que procedamos, no interior do campo da reabilitação, à crítica aos ideários universalistas de homem-padrão, assim como aos pressupostos mesocráticos, burgueses e eurocentrados sobre a organização da vida em sociedade. Porquanto não mais podemos assumir em nossa prática clínico-política o ideal de que o fundamento do contrato social, da cidadania desejada ou da democracia representativa defendida como tal possa emanar tão somente de indivíduos fortes, bem ajustados, totalmente autônomos e por completo racionais. Como argumenta Maffesoli (2011, p. 14), o cumprimento da vida social é antes de tudo fusional, afetivo, gregário:

Mais vale reconhecer que, em vez de um social racionalmente pensado e organizado, a socialidade nada é senáo uma concentração de pequenas tribos, dedicadas, de uma maneira ou de outra, a se ajustar, se adaptar e a negociar entre si. [...] Redes de redes em que o afetivo, o sentimento, a emoção sob suas diversas modulaçóes, têm um papel essencial.

Sobre essa estrutura societal os efeitos terapêuticos e mutagênicos da reabilitação estão diretamente associados à sua capacidade de catalisar os sentimentos de filiação, as simbioses afetuais e os processos de contaminação e transformação social que esses fenômenos não deixam de suscitar (Maffesoli, 2011). Contudo, essa catálise requer que estejamos radicalmente abertos ao inedistismo e à polissemia da experiência humana e que sejamos capazes de auxiliar os pacientes a viverem o presente de modo a sobrepujarem representaçóes inertes e apáticas de si mesmos e de seus passados. Bricolar corpo, desejo e memória na produção de porvires de plurais texturas, contornos e matizes existenciais, conditio sine qua non para efetiva mudança clínica, está assim na reabilitação inseparável da ação micropolítica de transformação social, ou seja, da habilidade de cavar sulcos na invariância axiológica das normoses sociais, de produzir e ampliar dobras, estrias nos territórios urbanos e subjetivos esticados, homogeneizados e compartimentalizados pelos regimes de saber-poder hegemônicos, irrompendo a falta, a falha, a quebra de sentido nos protótipos de normalidade e nos ideários de controle que travestem a historicidade, a fluidez e a provisoriedade da vida (Palombini, 2009; Figueiredo, 1993; Araújo, 2005). 


\section{Acompanhamento Terapêutico na prática da Reabilitaçáo Psicossocial}

O AT é um dispositivo clínico cuja intervenção centra-se nos vínculos e relaçōes construídos entre o paciente e sua rede social. Trata-se de uma forma de cuidados intensivos em saúde mental, articulada à prevenção de riscos, ao manejo terapêutico e à promoção de saúde, na qual o setting clínico afasta-se dos enquadres dos consultórios tradicionais, constituindo-se na própria relação entre o acompanhante e o acompanhado a partir de sua circulação conjunta por entre os espaços urbanos, os locais de trabalho e lazer e o ambiente doméstico em que ocorrem as rotinas cotidianas deste (Galdós \& Mandelstein, 2009). Tal deslocamento do espaço terapêutico, caracteristicamente operado pela atitude de permanecer junto através da prática de saídas pela cidade, consiste na tentativa de compreender a experiência do sofrimento à medida que se busca acompanhar a angústia, compartilhar o estranhamento e testemunhar as dificuldades e tentativas de adaptaçáo do paciente (Estellita-Lins, Oliveira, \& Coutinho, 2009). Quando da aplicação desse dispositivo junto a egressos de longas internaçôes, objetiva-se, por meio da construção de enlaces pragmáticos e existenciais que o rearticulem ao espaço social, analisar e modificar sua qualidade de vida no intuito de minorar as deficiências decorrentes do estado de dano, prevenir o isolamento e a cronificação e desenvolver capacidades funcionais para a estruturação de um devir autônomo e com sentido. Nessa direção, funciona como "uma atividade clínica, em movimento, que procura desinstalar o indivíduo de sua situação de dificuldade para poder recriar algo novo na sua condição" (Pitiá \& Furegato, 2009, p. 73). Logo, constitui-se como uma estratégia terapêutica nômade a qual, orientada à indução de aberturas emancipatórias para a vida, aponta para a recuperação da autoestima, a integração comunitária e o empoderamento social e político de seus usuários.

$\mathrm{Na}$ observância aos seus referenciais reformistas e antimanicomiais, bem como na potencialidade que apresenta para produzir novas topologias subjetivas e culturais em torno da reinserçâo social, o AT articula-se às formulaçóes conceituais e políticas da RP de orientação sociopolítica, embora por meio de lastres teóricos ainda pouco diagramados na literatura especializada. As proposiçôes terapêuticas desses dois modelos encontram convergência na ideia de que as possibilidades de reintegração social de indivíduos com transtornos mentais não residem somente na reestruturação e avanço dos serviços e tecnologias assistenciais, mas igualmente na efetivação de diretrizes políticas para a desconstrução dos mecanismos de exclusão asilar e de estratégias sociais direcionadas à transformação das segregatórias formas contemporâneas de interação com a diferença. Por- 
tanto, para ambas as formas clínicas, a ampliação dos gradientes de autonomia de seus usuários está articulada ao enfrentamento e gradual desmonte dos obstáculos simbólicos e materiais, das violações de direitos e das desvantagens a que eles são cotidianamente submetidos em função de suas peculiares condições.

O desafio é produzir movimentos e articulações dotados de propósito clínico sobre o estado inercial que decorre da sujeição dos usuários às contínuas e irrestritas exigências de ajustamento, buscando favorecer modos singulares de inclusão desses indivíduos nos processos de trocas e intercâmbios sociais (Fiorati \& Saeki, 2006). Não obstante, conforme apontamos anteriormente, qualquer processo de inclusão desconectado da dimensão pragmática da vida ou, em outro extremo, restrito a uma imposição acrítica de modos idealizados e apriorísticos de funcionamento, tende a privar os indivíduos com transtornos mentais da possibilidade de agir sobre a realidade para recriá-la, pressionando-os a situaçóes de obediência e submissão. Logo, podemos considerar que a eficácia terapêutica de ambos os dispositivos clínicos em produzir inclusóes sociais geradoras de autonomia está ligada à competência que manifestam em auxiliar os pacientes na experimentação de estratégias próprias de ação, adaptadas às suas particularidades, contudo suficientemente flexíveis para ampliar suas capacidades relacionais.

Com efeito, o planejamento e a criação de mecanismos por meio dos quais possam desenvolver formas próprias e efetivas de funcionamento cotidiano e interação social visa minorar o impacto das deficiências que lhes ocorrem a fim de provocar a gradual expansão de seus campos de contratualidade social. Nesse tocante, a produção do AT apresenta forte conexão às práticas reabilitativas de matriz sociopolítica, pois, semelhante a estas, alicerça o processo de recuperação dos sujeitos - diz-se da capacidade de produzir vida com sentido social e existencial - em suas inserçóes diretas nos sistemas de trocas e negociaçóes sociais que articulam os processos de produção material e simbólica da vida (Saraceno, 1996; Fiorati \& Saeki, 2006).

Nesse contexto, o enfoque na concretude material do ambiente e das relaçóes cotidianas do paciente, característica compartilhada entre a RP de matriz sociopolítica e o AT, permite o mapeamento dos relacionamentos familiares e afetivos, das redes sociais e dos padróes de interação a partir dos quais ele organiza suas estratégias de subjetivação, bem como seus modos de pertencimento social. Inteirar-se dessas informações requer, contudo, a compreensão ampla e sistêmica de seus hábitos e rotinas. A partir da observação de como administra e cumpre suas atividades corriqueiras numa dada extensão do dia, de que forma executa seus afazeres domésticos, como utiliza seu tempo livre (ou que funções atribui para o ócio), por quais circuitos urbanos transita, pode-se entrever como significa 
os papéis sociais que arroga para si, as heterogêneas produçóes desejantes que articula, seu lugar na estrutura familiar, sua forma de perceber a passagem do tempo.

É preciso identificar os interesses e as potencialidades manifestos na execução das tarefas diárias, mas também avaliar o manejo no trato com os problemas que enfrenta tanto no ambiente doméstico quanto nos espaços públicos e coletivos da rua. Deve observar-se, pois, suas habilidades sociais, aptidóes laborais, níveis de destreza no autocontrole e higiene, padróes de locomoção, modos de comunicação, assim como demais capacidades envolvidas na ampliação de seus gradientes de autonomia, aspectos que são fundamentais no processo de reabilitação. Assim sendo, a participação intensiva nas atividades cotidianas do paciente possibilita ao acompanhante o reconhecimento dos diversos recursos que mobiliza como parte de sua estratégia de vida. Com base nisso é possível reconhecer os objetivos a serem traçados e os caminhos a serem percorridos para minorar as perdas funcionais vivenciadas em virtude do transtorno mental e/ou dos efeitos iatrogênicos da internação asilar (Estellita-Lins et al., 2009).

Decerto, o manejo terapêutico dado sob as vicissitudes do ambiente natural do paciente requer flexibilidade e rápida capacidade de adaptação. Isso não significa que o AT seja uma prática desprovida de propósito clínico ou exercida sem devido planejamento. Faz-se sob diversos pretextos - compras no mercado, consulta médica no posto de saúde, abertura de conta em banco, visita a algum parente ou um simples passeio pela rua - e obedece ao governo de diferentes regimes intensivos, assumindo formas que se alternam conforme os acasos e desvios ocorrem aos trajetos percorridos. Ao pôr-se em movimento junto ao acompanhado, o acompanhante faz operar o saber que repousa em sua formação teórico-técnica, mas não como uma reprodução amórfica de esquematizaçóes padronizadas e sim por meio da fluidez de um conhecimento tácito, uma espécie de "saber de ofício, no qual as teorias estão impregnadas pela experiência pessoal e as estão impregnando numa mescla indissociável” (Figueiredo, 1993, p. 91).

\section{Reabilitação Psicossocial na prática do Acompanhamento Terapêutico}

No contexto da desinstitucionalização de egressos de longas internações asilares o acompanhante necessita apropriar-se dos modelos teóricos e das práticas de reabilitação extramuros, fornecendo-lhes um lugar e um propósito clínico capazes de fazer frente às dificuldades vividas pelos acompanhados, sejam como consequência direta da enfermidade psiquiátrica, sejam procedentes das múltiplas 
violaçôes a que foram submetidos sob duradouros períodos de clausura, as quais lhes dificultam ou impedem o desenvolvimento das capacidades funcionais nos diferentes aspectos da vida diária, interferindo na consecução de sua autossuficiência econômica e protagonismo social (Estellita-Lins et al., 2009; Araújo \& Del Prette, 1998).

A passagem por uma instituição asilar constitui subjetividades fadigadas, em estilhaços, sufocadas por não encontrarem tradução nas lógicas discursivas tradicionais (Basaglia, 2005). Rupturas e descontinuidades operadas entre a vida que antecedera a internação e aquela resultante do processo de institucionalização tendem a produzir nas pessoas danos cognitivos severos usualmente acompanhados da inabilidade de manterem formas estáveis de autorrepresentação, gerando-lhes toda sorte de dificuldades para o estabelecimento de comunicação (Basaglia, 1968/2001). Ademais, em virtude do prolongado isolamento social, dos efeitos iatrogênicos dos psicofármacos consumidos, dos agravos provocados pela exposição crônica e duradoura ao ambiente asilar, da opressão física e psíquica do tratamento manicomial, habilidades básicas para viver de modo autônomo, como capacidade para asseio, compras, locomoção, perdem-se ou degeneram-se no espaço asilar (Amarante, 1996).

Concretamente, a manutenção de uma vida autônoma fora dos muros do manicômio e a ampliação do engajamento do paciente na tomada de decisóes acerca de seu tratamento (seja no âmbito preventivo, assistencial ou reabilitativo) requerem a progressiva minoração de suas limitaçóes funcionais através do ensino de habilidades e competências para a vida diária e a introdução de mudanças no ambiente em que vive (Galdós \& Mandelstein, 2009). Tais açóes devem buscar ofertar suporte residencial, laboral e educativo personalizado em função das demandas singulares do acompanhado e das configuraçóes de seu entorno social. Além disso, precisam ser capazes de articular a participação do usuário, amigos e familiares na escolha das medidas a serem adotadas e no controle sobre suas aplicações de modo a corresponsabilizá-los pela condução do processo terapêutico.

$\mathrm{Na}$ condição de acompanhantes, buscamos, então, trabalhar junto aos acompanhados um variado espectro de habilidades que pode ir desde açóes aparentemente simples como, por exemplo, utilizar uma chave a atividades de maior complexidade tal qual a aquisição de competências para o manejo e consumo responsável da medicação. $\mathrm{O}$ aprendizado ocorre in vivo e faz uso do potencial terapêutico presente em suas experiências cotidianas. Nesse processo o acompanhante constitui um sistema de suporte temporário, semelhante a um cadafalso, permitindo a evolução progressiva das possibilidades de desenvolvimento dos acompanhados. Buscando estabelecer uma relação de interação horizontal, os 
assiste proporcionando-lhes apoio e suporte, de modo que se sintam confiantes para testar uma habilidade ou trabalhar uma nova competência. É preciso atentar, contudo, que a forma e o tempo de aprendizagem são tâo diversos e complexos quanto os processos de desenvolvimento dos acompanhados e, por isso, junto a cada um deles, torna-se necessário acordar um programa individualizado cujos propósitos devem se articular a seus interesses, recursos e limitaçóes.

O vínculo pactuado no AT caracteriza-se por uma construção partilhada de saberes e habilidades e opera no sentido de possibilitar que os pacientes reconheçam e interfiram nas estratégias, conhecimentos e tecnologias utilizados na resolução de um problema ou conclusão de uma tarefa. Trata-se de estruturar um ambiente de aprendizado dialógico a partir do qual possam integrar as dificuldades experienciadas à assimilação gradual das sub-habilidades requeridas para execução da atividade objetivada. Todavia, para além da cópia de um modelo de ação rígido e pré-formulado, busca-se incitar a apropriação das ferramentas de mediação, utilizadas durante a aquisição das novas competências, permitindo-lhes a experimentaçáo construtiva com os modelos com os quais interagem e sua transformação em novas formas. Essa estratégia gradualmente possibilita aos acompanhados a gestáo autônoma e voluntária de seus próprios processos de aprendizagem, o que implica na ampliação da capacidade para reconhecimento dos limites de uso dos modelos desenvolvidos e numa maior compreensão das consequências resultantes de suas aplicações práticas.

O processo de reabilitação assistida no contexto do AT visa, nessa perspectiva, desvencilhar os acompanhados das restrições de uma dada situação, ora auxiliando no desenvolvimento de uma habilidade emergente, ora tornando possível a execução de uma capacidade já efetivada sob condiçóes mais complexas. Em ambos os casos, o conjunto de funçôes psicológicas (tais como atenção volitiva, controle consciente do comportamento, pensamento, linguagem, memória voluntária) que se articula ao planejamento, execução e avaliação da competência trabalhada sofre uma reorganização estrutural qualitativa. $\mathrm{O}$ reposicionamento, contração, desintegração e decomposição das funçóes previamente consolidadas institui períodos críticos cujo ponto de culminância torna-se o locus no qual um ciclo de reorganização encontra término (Valsiner \& Van der Veer, 1991).

Tal dialética permite a reconfiguração da estrutura dos processos psicológicos e, assim sendo, torna possível o engendramento da competência objetivada. Contudo, o remodelamento dessa estrutura, tendo por base a transformação de suas funçóes constitutivas anteriores, ocorre sempre de maneira heterocrônica. Uma vez que, no curso do aprendizado de uma competência, os pontos finais de mutação das diferentes funções psicológicas envolvidas diferem, num certo 
instante algumas dessas funçóes estarão se aproximando de seus respectivos momentos de consolidaçáo, enquanto outras já estarão consolidadas. É precisamente sobre as funções ainda não transformadas por completo, porém em presente mudança, que os esforços assistenciais do acompanhante devem se focar.

A cada passo do processo, as intervençôes instrucionais do acompanhante integram a situação de resolução de problemas, constituindo não um terceiro termo exterior à interação acompanhado $\leftrightarrow$ tarefa ambiental, mas integrando o próprio arranjo ensino-aprendizagem. Mediante seu corpo, palavra e atos, procura ofertar suporte aos esforços do acompanhado, funcionando como uma estrutura de apoio vicária cuja forma se estabelece na articulação entre os saberes e hipóteses do paciente e a identificação pelo acompanhante de sua perícia sobre a atividade trabalhada. Talvez pudéssemos comparar essa estrutura de apoio aos andaimes que suportam um edifício que está sendo construído e que vão sendo retirados à medida que a armação em construção vai tornando-se capaz de sustentar-se sem ajuda (Fino, 2001). De forma semelhante, quando apto a exercer controle individual sobre uma açáo em desenvolvimento, o acompanhado deverá ser progressivamente conduzido a executá-la sem auxílios. Aqui a construção dos andaimes náo procede adiante do tempo de aprendizagem do paciente; ao contrário, buscando acompanhar o ritmo com que seus sistemas funcionais se reorganizam, tenta adaptar-se às mudanças nos tipos de atividades psicológicas utilizadas e às variaçōes na forma e frequência das experiências cotidianas.

Direcionadas para a aquisição ou recuperação de aptidóes importantes à reinserção social, as estratégias de reabilitação em cenários interativos resultam da complementaridade da ação conjunta acompanhado-acompanhante. Essa ação conjunta, guiada por significados e propósitos partilhados, é constantemente reelaborada pelos esforços coconstrutivos de seus operadores e, em vista disso, pode ser percebida adequadamente apenas em sua forma dinâmica de processo. Contudo, não ocorre de modo unilateral: sofre intermitentemente ações do ambiente no qual opera, transformando a si própria conforme sobre ele produz transformação. Por outro lado, porquanto tal ação tende a conduzir, no interior da reabilitação, a díade acompanhado-acompanhante a um ambiente social cada vez mais heterogêneo, sua operacionalização requer a coordenação dialógica - frequentemente simultânea - de diferentes mecanismos de aprendizagem (tais como dispositivos de memorização, sistemas de referência e planejamento de estratégias). A conceituação da reabilitação como um arranjo temporário e em contínua mutação no qual os participantes estabelecem seus papéis ativamente ao compartilhar o agenciamento de múltiplos espaços e tempos desenvolvimentais não só enturva as possibilidades de prediçấo exata e apriorística de seus resultados futuros como 
é antitética à utilização de andaimes hirtos, impostos ao usuário e construídos à revelia de suas vontades.

Assim sendo, os processos reabilitativos substancializados no AT não podem ser entendidos como meios para o enquadramento dos acompanhantes em modelos instituídos de ação, pensamento e afetação. Não se trata de habilitar o incapaz, mitigando seu desajuste para trazê-lo de volta à normalidade, mas sim de produzir, a partir de suas potencialidades atuais, itinerários para a invenção de novas possibilidades de vida, tão livres, plurais e autônomas quanto possíveis (Saraceno, 1999). Logo, para que se possa intervir sobre os processos psicossociais que operam no domínio da transformaçáo presente-futuro dos sujeitos com transtornos mentais, é preciso reconhecer que não há nenhum déficit entre a experiência da loucura e as prerrogativas da razão técnico-científica. Isso significa que o devir do louco não se reduz a um distúrbio à espera de correção, suas heteróclitas e singulares manifestações não são degenerações comportamentais tampouco precisam obedecer a um ideal normativo de conduta para possibilitarem a efetivação da reinserção social.

Conforme apontam Pinto e Ferreira (2010), a tentativa de equalizar o paciente, seja para restituir-lhe o suposto equilíbrio que houvera perdido, seja para reparar suas dificuldades de adaptaçáo no afấ de torná-lo igual aos demais, inscreve sua complexa existência (presente e vindoura) no âmbito da negatividade, denotando, assim, a premência de um "conserto" para sua loucura, de um retorno à normalidade. Estratégias reabilitativas desenvolvidas nessa direção tendem a ensejar a reedição das práticas e sentidos manicomiais, instaurando entre paciente e terapeuta relaçóes de poder assimétricas alicerçadas na infantilização e tutela da loucura.

Sabemos, contudo, que intervençóes reabilitativas junto a pessoas com transtornos mentais graves e crônicos requerem soluçôes transdisciplinares e flexíveis somente possíveis quando alicerçadas num contínuo diálogo entre os diversos atores e serviços que participam do processo de reinserção. Tal abertura exige a transformação dos contingenciamentos clínico-políticos que conformam os interesses práticos e afetivos dos acompanhados, terapeutas e familiares em planos hierarquicamente distintos. Nesse sentido, a horizontalização da produção do AT favorece um intercâmbio concreto de saberes, permitindo a intensificação do conhecimento mútuo e dos vínculos de cuidado estabelecidos durante o tratamento. Com efeito, a aquisição e ampliação de informaçóes tais como hábitos e rotinas cotidianas do paciente, seu histórico de vida, evolução clínica, planos psicoterápicos e farmacológicos pregressos abre ao terapeuta a possibilidade de articular a experiência de sofrimento a uma série de fatores que a contextualizam 
e a colocam mais próxima de sua compreensão (Saraceno, Asioli, \& Tognoni, 2001). Para o acompanhado, o intercâmbio de saberes junto ao terapeuta auxilia na estruturação de um espaço expansivo de questionamento, interferência e apropriação do manejo clínico, o que pode efetivamente ampliar sua participação na escolha das medidas terapêuticas e no exercício do controle sobre o tratamento.

Ao interagir com o paciente e seus familiares, um diálogo franco e aberto proporciona oportunidades para reconhecimento e avaliação das mudanças experimentadas nos diferentes momentos da reabilitação. Igualmente, serve à problematização de certos vieses, amiúde construídos quando há recusa a discutir e investigar as discordâncias, os questionamentos e as negaçóes do paciente (os quais tendem a ser de imediato interpretados como estratagemas, desvios de conduta daquela que costumava manifestar ou da que se espera que apresente - ou provas de sua inaptidão de tomar decisóes), fazendo emergir novas aberturas comunicacionais que podem permitir ao terapeuta e aos familiares uma compreensão mais ampla das razóes que impulsionam as escolhas do paciente e dos significados que suas instituiçóes, em ato, representam (Saraceno et al., 2001).

Todavia, comunicar-se por meio da fala e da escuta requer, para além da supracitada abertura comunicacional, uma língua comum. Posto que reconheçamos que, na ausência de fundamentos e garantias indubitáveis, nosso discurso é tão discutível, incerto e questionável quanto o do louco e que, portanto, a imposição de uma lógica comunicativa não só é improfícua para o estabelecimento de liames dialógicos, mas trata-se de um exercício de violência simbólica que oblitera os meios expressivos de um dos falantes, torna-se necessário a construção de referenciais comuns, em que os diferentes participantes do diálogo possam relativizar momentaneamente seus próprios pressupostos (Deleuze \& Guattari, 1980/2011; Araújo, 2005).

Tal ação, a qual certamente exige dos terapeutas o distanciamento das invariantes axiológicas, formulaçóes estáticas e dos sentidos homogêneos historicamente produzidos em torno da diferença, pode auxiliar a alcançar dois propósitos fundamentais ao estabelecimento de uma comunicação paritária, aberta e genuinamente autêntica, tais sejam: o abandono da doutrinação pedagógica e da correção normatizadora das falas, por um lado; por outro, a transformaçáo de uma escuta kafkiana que toma todas as falas do louco contrárias às expectativas racionais de seus interlocutores como evidências de sua incapacidade - protestos razoáveis são "negaçôes", medos válidos, "paranoia", instintos de sobrevivência, "mecanismos de defesa". Logo, para que essa estratégia possa ganhar solidez é preciso que o acompanhante esteja preparado para, como defende Basaglia (2005), questionar e desnaturalizar em sua prática as categorias psiquiátricas que amoldam a loucura 
nas noções de periculosidade, defeito e incapacidade. É que a naturalização dessas categorias opera de forma a ocultar o "duplo da doença mental", obliterando a ligaçáo intrínseca entre sociedade/sujeito que enlouquece por meio da objetificação completa do indivíduo que sofre e da legitimação dos estigmas equacionados sobre a negação de sua subjetividade. Desse modo, não só destitui-se de valor o conhecimento desse sujeito, confere-se a ele uma identidade marginal e doente a partir da qual passa a ser visto como fonte de contágio ou desordem social a ser permanentemente vigiada e contida (Amarante, 1996).

Com efeito, é precisamente tal forma de interação com a alteridade que a clínica do AT deve auxiliar a transformar para efetivar espaços concretos de recontratualização social. Pois sobre o vasto capital de verdades produzido na cultura manicomial com base naquilo que se supóe ser o louco e a sua loucura - meras quimeras científicas - assentam-se os juízos morais e os constructos discursivos (pretensamente a-históricos e universais) através dos quais aprendemos a lidar, olhar e sentir a experiência do sofrimento psíquico. Assim sendo, o aparato político da cultura manicomial apaga a utopia da cidade como polis, configurando cenários urbanos que reproduzem segregaçóes, multiplicam estigmas, mantendo a constância de um único devir: gestar novas condiçôes de possibilidade para a medicalização e apartaçáo daqueles cujos valores, atos ou opinióes náo se adequam ao proposto como ideal, desejável ou permitido pelo ideário capitalístico de controle e submissão da vida.

Podemos então concluir que a prática do AT se constitui sobre a decodificação e o desmonte dos fracionados e fragmentadores procedimentos da terapêutica asilar, abstraídos da materialidade da vida, limitados aos parâmetros nosográficos da taxonomia psiquiátrica e intransitivamente dirigidos à patologização das condutas desviantes. A articulaçẫo desse dispositivo às proposiçóes reabilitativas de matriz sociopolítica amplia seu inventário de estratégias clínicas e, portanto, suas possibilidades de intervenção através das múltiplas redes na qual opera. Por outro lado, a reabilitação, quando conectada à prática do AT, pode expandir seu escopo de atuação para além dos settings clínicos formais e buscar, na solidez dos espaços urbanos, a ruptura das práticas e discursos que alimentam o aparato político e tecnocrático da cultura manicomial, auxiliando assim na construção social de novas formas de cuidado e interação com a experiência do sofrimento psíquico baseados na liberdade, na autonomia e no exercício de direitos (Nicácio \& Campos, 2004). Tal ruptura, em que vicejam possibilidades de invenção de um novo lugar social para a loucura, é o próprio desafio da reinserção: transformar a cidade em seu ideal de polis, espaço de convivência e respeito mútuo produzido sobre a arborescência contínua de conflitos e negociaçôes, campo de experimentação 
de vida, de encontros, de sociabilidades, tão logo território de estranhamento e diferenciação, mutante, heteróclito e multifário (Palombini, 2009).

\section{Referências}

Amarante, P. (1996). O homem e a serpente: outras histórias para loucura e psiquiatria. Rio de Janeiro: Fiocruz.

Araújo, A., \& Del Prette, A. (1998). O acompanhamento terapêutico no processo de reabilitação psicossocial de pacientes psiquiátricos com longa história de internação. In M. C. Marquexine, M. A. Almeida, E. E. O. Tanaka, N. N. R. Mori, \& E. M. Shimazaki (Eds.), Perspectivas interdisciplinares em Educação Especial (pp. 203-206). Londrina: Editora da Universidade Estadual de Londrina.

Araújo, F. (2005). Um passeio esquizo pelo acompanhamento terapêutico: dos especialismos clínicos à política da amizade. Rio de Janeiro: Editora Niterói.

Baldi, C. A. (2013). Contra as visões de "baixa intensidade" dos direitos humanos. Carta Maior. Recuperado em 30 de maio, 2013, de <http://www.cartamaior.com.br/templates/ analiseMostrar.cfm?coluna_id=6044>.

Basaglia, F. (2001). A instituição negada: relato de um hospital psiquiátrico. Rio de Janeiro: Graal. (Trabalho original publicado em 1968)

Basaglia, F. (2005). Um problema de psiquiatria institucional: a exclusão como categoria sociopsiquiátrica. In P. Amarante (Ed.), Escritos selecionados em saúde mental e reforma psiquiátrica (pp. 35-59). Rio de Janeiro: Garamond.

Benetton, M. J. (1996). Terapia ocupacional e reabilitação psicossocial: uma relação possível? In A. M. F. Pitta (Ed.), Reabilitação Psicossocial no Brasil (pp. 143-149). São Paulo: Hucitec.

Birman, J. (1992). A cidadania tresloucada: notas introdutórias sobre a cidadania dos doentes mentais. In B. Bezerra, \& P. Amarante (Eds.), Psiquiatria sem hospício: contribuiçôes ao estudo da reforma psiquiátrica (pp. 71-90). Rio de Janeiro: Relume-Dumará.

Cases, J. G., \& González, A. R. (2010). Programas de rehabilitación psicosocial en la atención comunitaria a las personas con psicosis. Clínica y Salud, 21(3), 319-332.

Deleuze, G., \& Guattari, F. (2011). Mil platôs: capitalismo e esquizofrenia, v. 2. São Paulo: Editora 34. (Trabalho original publicado em 1980).

Dutra, E. (2004). Consideraçóes sobre as significaçóes da psicologia clínica na contemporaneidade. Estudos de Psicologia, 9(2), 381-387.

Estellita-Lins, C., Oliveira, V. M., \& Coutinho, M. F. (2009). Clínica ampliada em saúde mental: cuidar e suposição de saber no acompanhamento terapêutico. Ciência \& Saúde Coletiva, 14(1), 195-204.

Figueiredo, L. C. (1993). Sob o signo da multiplicidade. Cadernos de Subjetividade, 1, 89-95. 
Fino, C. N. (2001). Vygotsky e a Zona de Desenvolvimento Proximal (ZDP): três implicaçóes pedagógicas. Revista Portuguesa de Educação, 14(2), 273-291.

Fiorati, R. C., \& Saeki, T. (2006). O acompanhamento terapêutico: criatividade no cotidiano. Psychê, 10(8), 81-90.

Galdós, J. S., \& Mandelstein, A. C. (2009). La intervención socio-comunitaria en sujetos con trastorno mental grave y crónico: modelos teóricos y consideraciones prácticas. Intervención Psicosocial, 18(1), 75-88.

Guerra, A. M. C. (2004). Reabilitação psicossocial no campo da reforma psiquiátrica: uma reflexão sobre o controverso conceito e seus possíveis paradigmas. Revista Latino-americana de Psicopatologia Fundamental, 7(2), 83-96.

Lussi, I. A. O., Pereira, M. A. O., \& Pereira Junior, A. (2006). A proposta de reabilitação psicossocial de Saraceno: um modelo de auto-organização? Revista Latino-Americana de Enfermagem, 14(3), 448-456.

Maffesoli, M. (2011). O narcisismo intelectual. In G. Grelet (Ed.), Teoria-rebeliáo: um ultimato (pp. 11-15). Rio de Janeiro: Novamente.

Nicácio, F., \& Campos, G. W. S. (2004). A complexidade da atenção às situaçóes de crise: contribuiçôes da desinstitucionalização para a invenção de práticas inovadoras em saúde mental. Revista de Terapia Ocupacional da USP, 15(2), 71-81.

Palombini, A. L. (2009). Utópicas cidades de nossas andanças: flânerie e amizade no acompanhamento terapêutico. Fractal, 21(2), 295-317.

Pinto, A. T. M., \& Ferreira, A. A. L. (2010). Problematizando a reforma psiquiátrica brasileira: a genealogia da reabilitação psicossocial. Psicologia em Estudo, 15(1), 27-34.

Pitiá, A. C. A., \& Furegato, A. R. F. (2009). O Acompanhamento Terapêutico (AT): dispositivo de atenção psicossocial em saúde mental. Interface, 13(30), 67-77.

Pitta, A. M. F. (1996). O que é Reabilitação Psicossocial no Brasil, hoje? In A. M. F. Pitta (Ed.). Reabilitação Psicossocial no Brasil (pp. 19-26). São Paulo: Hucitec.

Rodrigues, H. B. C. (2000). À beira da brecha: uma história da Análise Institucional francesa nos anos 60. In P. Amarante (Ed.), Ensaios: subjetividade, saúde mental, sociedade (pp. 195256). Rio de Janeiro: Fiocruz.

Saraceno, B. (1996). Reabilitação psicossocial: uma estratégia para a passagem do milênio. In A. M. F. Pitta (Ed.), Reabilitação Psicossocial no Brasil (pp. 13-18). São Paulo: Hucitec.

Saraceno, B. (1999). Libertando identidades: da reabilitação psicossocial à cidadania possivel. Rio de Janeiro: Instituto Franco Basaglia/Té Cora.

Saraceno, B., Asioli, F., \& Tognoni, G. (2001). Manual de Saúde Mental. São Paulo: Hucitec. Valsiner, J., \& Van der Veer, R. (1992). The encoding of distance: The concept of the Zone of Proximal Development and its interpretations. In R. R. Coking, \& K. A. Renninger (Eds.), The Development and Meaning of Psychological Distance (pp. 35-62). Hillsdale: Lawrence Erlbaum Associates. 


\section{Nota}

${ }^{1}$ Em observância à classificação terminológica já adotada por Guerra (2004), referenciar-nos-emos doravante ao conjunto de tais princípios (e das práticas reabilitativas deles decorrentes) como modelo de matriz ou orientaçáo sociopolítica.

Recebido em 9 de setembro de 2013 Aceito para publicaçáo em 25 de setembro de 2014

DOI: $10.1590 / 0103-56652015000100006$ 